\title{
Caracterización poscosecha de frutos de tacaco (Sechium tacaco (Pittier)) en Cartago, Costa Rica ${ }^{1}$
}

\section{Postharvest characterization of tacaco (Sechium tacaco (Pittier)) fruits in Cartago, Costa Rica}

\author{
María del Milagro Cerdas-Araya ${ }^{2}$,Johanny Castro-Chinchilla ${ }^{2}$
}

\section{RESUMEN}

El objetivo del presente trabajo fue realizar una caracterización poscosecha de frutos de tacaco de diferente edad cronológica. Durante julio y agosto de 2014 y, enero y febrero de 2015 se evaluaron frutos recién cuajados, con y sin espinas, procedentes de Cartago, Costa Rica. A partir de los siete días después del cuaje del fruto en tacacos sin espinas (TSE) y ocho días en tacacos con espinas (TCE), se evaluó el peso, y el largo y ancho del fruto, presencia y endurecimiento de las espinas, y aparición de fibra. El largo y grosor de la semilla, la firmeza, y el color externo de la cáscara, fueron evaluados a partir de los catorce días. En ambos materiales, el peso, el largo y ancho del fruto se estabilizaron a partir del día veintiuno, momento en el cual ocurrió la aparición de fibra y espinas, y se registró un incremento significativo en la firmeza, la cual alcanzó a los treinta días, valores de $80 \mathrm{~N}$ a $100 \mathrm{~N}$ en tacaco con espinas y hasta $129 \mathrm{~N}$ en frutos sin espinas. El color de la cáscara pasó de un verde amarillento en el estado inmaduro a verde grisáceo en el estado sazón a los treinta días, momento cercano a la abscisión del fruto. Antes del día veintiuno TSE o TCE, se pueden utilizar como frutos inmaduros, ya que no hay presencia de fibra; y la cáscara y las espinas aún no se han endurecido.

Palabras clave: fibras en el mesocarpo, semilla coriácea, frutos con espinas, frutos sin espinas.

\begin{abstract}
The aim of this work was to make a postharvest characterization of tacaco fruits in different chronological ages. During July and August of 2014, and January and February of 2015 newly set fruits, with or without thorns, from Cartago, Costa Rica were evaluated. Seven days after setting for the tacaco fruits without thorns (TWOT) and eight days after setting for the tacaco fruits with thorns (TWT), weight, length and width of the fruit, presence and hardening of the thorns, and emergence of fiber were evaluated. The length and thickness of the seed, the firmness, and external color of the peel, were evaluated after day fourteen. In both material, weight, length and width of the fruit stabilized after day twenty-one, moment in which fiber and thorns appeared, and a significant increase in firmness was registered, which by day thirty reached values of $80 \mathrm{~N}$ to $100 \mathrm{~N}$ in tacaco thorns and up to $129 \mathrm{~N}$ in thorn less fruits. The color of the peel went from a yellowish green in the unripen stage to a greyish green in the ripened stage by day thirty, close to the moment of the fruit's separation. Before day twenty-one TWOT or TWT, can be used as unripen fruit, because there isn't any presence of fiber; and the peel and thorns have not yet hardened.
\end{abstract}

Keywords: mesocarp fibers, leathery seed, fruits with thorns and fruits without thorns.

\footnotetext{
1 Recibido: 26 de noviembre, 2015. Aceptado: 14 de abril, 2016. Esta investigación formó parte del proyecto "Identificación de cambios poscosecha del fruto de tacaco (Sechium tacaco (Pittier)) para afinamiento de índices de cosecha según diferentes usos", adscrito a la Vicerrectoría de Investigación, Universidad de Costa Rica y financiado por el Laboratorio de Tecnología Poscosecha del Centro de Investigaciones Agronómicas de la Universidad de Costa Rica. San José, Costa Rica.

2 Universidad de Costa Rica, Centro de Investigaciones Agronómicas, Laboratorio de Tecnología Poscosecha. Apdo 2060, San José, Costa Rica.maria.cerdasaraya@ucr.ac.cr, johanny.castrochinchilla@ucr.ac.cr
} 


\section{INTRODUCCIÓN}

El tacaco (Sechium tacaco (Pittier) C. Jeffrey) es una hortaliza de la familia Cucurbitaceae, endémica de Costa Rica, por lo que su domesticación se hizo antes de la llegada de los españoles, y con respecto al consumo, el mismo se da exclusivamente en el territorio costarricense (Sáenz, 1970; Lira, 1995; Missouri Botanical Garden, 2009).

El tacaco se encuentra sembrado en el Gran Área Metropolitana, como enredaderas en los árboles, alcanzando alturas de hasta cinco metros, no obstante, en los últimos años se han establecido la mayoría de plantaciones comerciales en la Zona Central Oriental, donde predomina la producción de otras cucurbitáceas como el chayote (Sechium edule). Actualmente, en el cantón de Paraíso y alrededores, se cuenta con aproximadamente 57 productores, y este fruto generalmente se comercializa en la mayoría de las ferias del agricultor y en los mercados tradicionales de el Gran Área Metropolitana. Lira (1995) indicó que como parte del proyecto "Banco de germoplasma de Sechium de Costa Rica", se registraron en 1995, cuatro materiales diferentes de tacaco, y Brenes et al. (1996) señalaron que dentro de estos materiales se encontraron variaciones en cuanto a cantidad y distribución de espinas y cantidad de fibra en el fruto.

El fruto del tacaco mide entre $4 \mathrm{~cm}$ y $7 \mathrm{~cm}$ de largo, es elipsoidal y aplanado, sin espinas o con un número variable de espinas agudas cerca de la base, las cuales se tornan duras en la madurez, con cinco suturas o surcos longitudinales; además posee una sola semilla plana que alcanza una longitud de hasta $0,6 \mathrm{~cm}$, con la testa dura y lisa, son de color verde oscuro y algunos cultivares presentan una red de fibras que predominan en el estado sazón, las cuales no se encuentran en los materiales más seleccionados (León 1987; Morales 1994).

El tacaco en estado inmaduro y el maduro o sazón, son parte tanto del recetario como de las tradiciones costarricenses desde hace siglos, sobre todo entre los adultos de cuarenta años o más. El uso más tradicional del tacaco en estado sazón es en "olla de carne", en merienda y en miel. No obstante, algunos autores citan diferentes usos culinarios para el fruto en estado inmaduro, entre ellos: picado con arroz, en "arroz guacho", en sopas y como minivegetal en ensaladas (Brenes, 2002; González, 2015). El tacaco tiene en su composición un mayor contenido de proteína, calcio, fósforo, niacina y vitamina $\mathrm{C}$ que el chayote, pepino, zucchini, melón y sandía; el contenido de hierro es más alto que el de pepino, zucchini, melón y sandía y con respecto a tiamina y rivoflavina, sus valores solo son superados por el zucchini (INCAP, 2007).

El cultivo de tacaco contribuye a la diversificación agrícola del país, pero actualmente hay poca investigación publicada y se ha señalado que existe un alto riesgo de erosión genética cultural, debido al desconocimiento y al poco uso de esta hortaliza por parte de las generaciones actuales. Lo anterior, se agudiza por factores tales como la expansión urbana, la deforestación y las preferencias culturales por alimentos de origen foráneo (Lira, 1995; Brenes y Chaves, 1996).

La Convención de Diversidad Biológica de 1994, en su artículo 3 , indica: "cada país y no la humanidad, es dueño de sus recursos genéticos y por lo tanto, su patrimonio se ve fortalecido por el germoplasma de las plantas útiles que posee" (Brenes, 2002); esto motivó el desarrollo de un proyecto para el rescate y conservación de recursos genéticos autóctonos. En este se mencionó que los materiales de tacaco que han sido sometidos a procesos de conservación presentan diferencias en aspectos de calidad, como la presencia de espinas y el contenido de fibras, que influyen en su comercialización (Brenes, 2002).

El objetivo del presente trabajo fue realizar una caracterización poscosecha de frutos de tacaco de diferente edad cronológica.

\section{MATERIALES Y MÉTODOS}

El trabajo se realizó en los meses de julio y agosto de 2014, y enero y febrero de 2015, en plantaciones de tacaco ubicadas en el Yas y La Flor de Paraíso en Cartago, Costa Rica. El análisis de los frutos se realizó en el Laboratorio de Tecnología Poscosecha del Centro de Investigaciones Agronómicas de la Universidad de Costa Rica.

El cantón de Paraíso se encuentra a 1333 msnm. En los meses de julio y agosto de 2014, prevaleció una temperatura y humedad relativa promedio de $18,9{ }^{\circ} \mathrm{C}$ y $93,1 \%$ respectivamente, mientras que en enero y febrero de 2015 , el promedio fue de 17,8 ${ }^{\circ} \mathrm{C}$ y $89,8 \%$ de humedad relativa, de acuerdo con datos suministrados por el Centro de Investigaciones Geofísicas de la Universidad de Costa Rica (CIGEFI) (Vargas-Castillo, comunicación personal, 2015).

En cada finca se seleccionó un área de aproximadamente $3500 \mathrm{~m}^{2}$, con una densidad de 
siembra de $8 \mathrm{~m} \times 8 \mathrm{~m}$, donde se marcó al azar un total de 610 frutos recién cuajados, mediante el uso de pintura y cintas con la fecha respectiva, los cuales se utilizaron posteriormente para los respectivos análisis poscosecha. Los materiales utilizados fueron: tacaco con espinas procedente de El Yas de Paraíso y tacaco sin espinas procedente de La Flor de Paraíso, y en ambos casos el material de siembra fue seleccionado por los agricultores de la zona, los cuales utilizaron como criterio la presencia o ausencia de espinas en el fruto.

Las evaluaciones poscosecha se realizaron a partir de los siete y ocho días después del cuaje del fruto, en frutos sin espinas y con espinas respectivamente, con excepción del largo y grosor de la semilla, firmeza y color, las cuales se evaluaron a partir de los catorce o quince días después del cuaje, momento en que el fruto alcanzó un tamaño adecuado para realizar dichas mediciones. Del total de frutos marcados, sobrevivió aproximadamente un $40 \%$, lo cual permitió muestrear treinta frutos con espinas y treinta frutos sin espinas en cada una de las evaluaciones, las cuales se realizaron hasta los 30 o 31 días, momento en el que ocurrió la abscisión de la mayoría de los frutos.

El peso del fruto se determinó mediante el uso de una balanza $( \pm 0,01)$; para medición de la longitud y ancho del fruto y, la longitud y grosor de la semilla, se utilizó un calibrador milimétrico "vernier". La determinación de firmeza $\left(\mathrm{N}=\mathrm{kg} \mathrm{m} / \mathrm{s}^{2}\right)$ se realizó en la sección media de una cara del fruto, mediante el uso de un penetrómetro Chatillón con punta dentada de $0,6 \mathrm{~cm}$ de diámetro y $0,5 \mathrm{~cm}$ de profundidad. La medición de color externo, se realizó en la sección central de ambas caras del fruto, para lo cual se empleó un colorímetro HP-C210, se registraron los valores de $\mathrm{L}^{*}, \mathrm{a}^{*} \mathrm{y} \mathrm{b}^{*}$, donde la variable $\mathrm{L}^{*}$ hace referencia a la luminosidad (0-100), $a^{*}$ indica variaciones de color entre rojo y verde $(60 \mathrm{a}-60)$ y $\mathrm{b}^{*}$ registra los cambios de tonalidad entre el amarillo y el azul (60 a -60), y mediante el uso de la ecuación $\left(\sqrt{ }\left(a^{2}+b^{2}\right)\right)$, de la escala CIELAB (Commission Internationale de l' Eclairage, por sus siglas en francés) (Minolta, 2007), se calculó el valor del croma. Para el tacaco con espinas se determinó, mediante evaluación visual, el momento de inicio de formación de espinas, definidas como espinas suaves, y posteriormente, mediante el quiebre manual, el inicio del endurecimiento de las mismas. En ambos materiales, se determinó el porcentaje de frutos en los cuales, al realizar un corte transversal, se observó la presencia de fibra formada y endurecida.
Los datos fueron analizados mediante ANDEVA, con separación de medias simples, DMS $(p<0,05)$ para cada variable y cada momento de evaluación, mediante el programa estadístico INFOSTAT, versión 2012 (INFOSTAT, 2012).

\section{RESULTADOS Y DISCUSIÓN}

\section{Peso del fruto}

El peso del fruto de tacaco (Figura 1), presentó un incremento significativo $(\mathrm{p}<0,05)$ a partir del día 17 del cuaje del fruto, en los frutos con espinas (Figura 1A), mientras que en el tacaco sin espinas, este aumento se observó a partir del día 14 (Figura 1B); este comportamiento se mantuvo hasta el día 21 en ambos materiales, alcanzándose aproximadamente un $85 \%$ del llenado durante este período.

\section{Largo y ancho del fruto y la semilla}

Las dimensiones del fruto y de la semilla, incrementaron significativamente a partir del día catorce en tacacos sin espinas o diecisiete en frutos con espinas y hasta el día veintiuno en ambos materiales (Figuras 2 y 3), tendencia similar a la observada en la variable ganancia de peso. El largo de la semilla alcanzó valores máximos de $3,4 \mathrm{~cm}$ y $3,6 \mathrm{~cm}$ en tacaco sin espinas (Figura 3 B y D) y con espinas (Figura $3 \mathrm{~A}$ y C), respectivamente. El aumento en el grosor de la semilla fue mayor en los frutos con espinas, ya que esta creció en promedio $0,34 \mathrm{~cm}$ entre el día 17 y la última evaluación, en comparación con los frutos sin espinas, donde el incremento fue de $0,11 \mathrm{~cm}$.

Antes del día catorce en el material con espinas y del día diecisiete en tacacos sin espinas, el crecimiento del fruto y de la semilla fue lento, ya que no hubo un incremento significativo de las dimensiones y del peso del fruto, así como de las dimensiones de la semilla, y a partir de este momento y hasta el día veintiuno en ambos materiales el fruto experimentó una fase de rápido crecimiento, donde se alcanzó aproximadamente un $85 \%$ del tamaño y peso final, lo que coincide con resultados que han sido informados en otros frutos similares como el chayote (Sechium edule), donde el mayor porcentaje de ganancia de peso ocurre durante los primeros veinte días de desarrollo del fruto (Ramírez et al., 1990; Gamboa, 2005). 

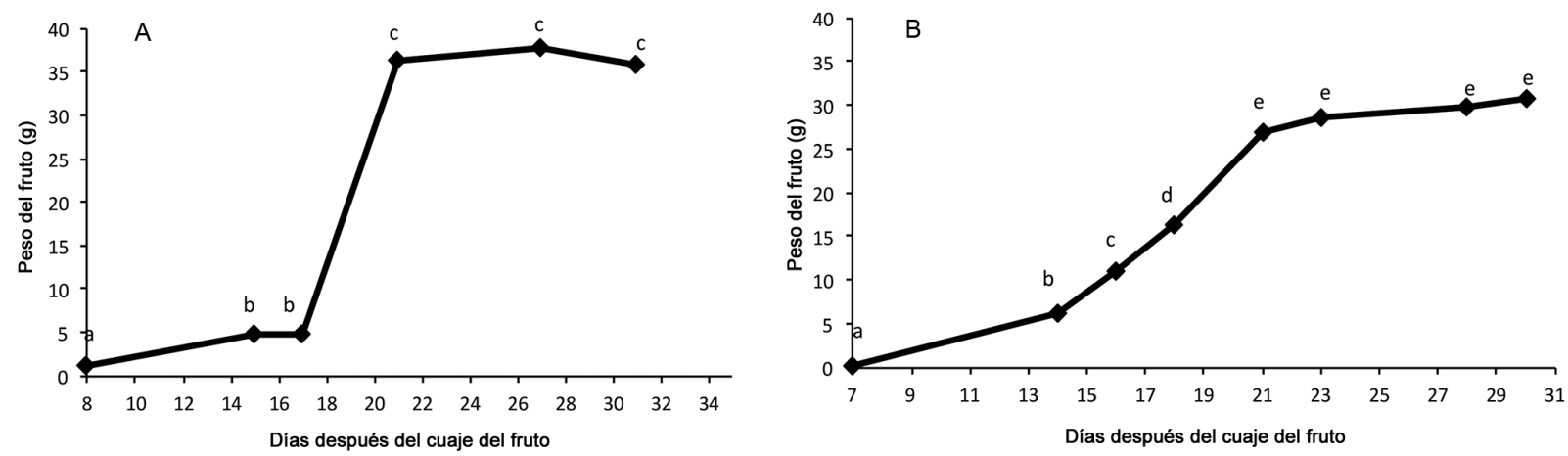

Figura 1. Peso de los frutos de tacaco (Sechium tacaco (Pittier) C. Jeffrey), con espinas (A) procedentes de El Yas de Paraíso, cosechados entre julio y agosto de 2014, y sin espinas (B) procedentes de La Flor de Paraíso, cosechados entre enero y febrero de 2015. Cartago, Costa Rica.

Medias con letras iguales no difieren entre si, según análisis de varianza y la prueba DMS $(\mathrm{p}<0,05)$.

Figure 1. Weight of tacaco fruits (Sechium tacaco (Pittier) C. Jeffrey), with thorns (A) from El Yas Paraíso, harvested between July and August 2014; and without thorns (B) from La Flor, Paraíso, harvested between January and February 2015. Cartago, Costa Rica.

Different letters mean statistical differences, according to variance analysis, LSD $(\mathrm{p}<0.05)$.
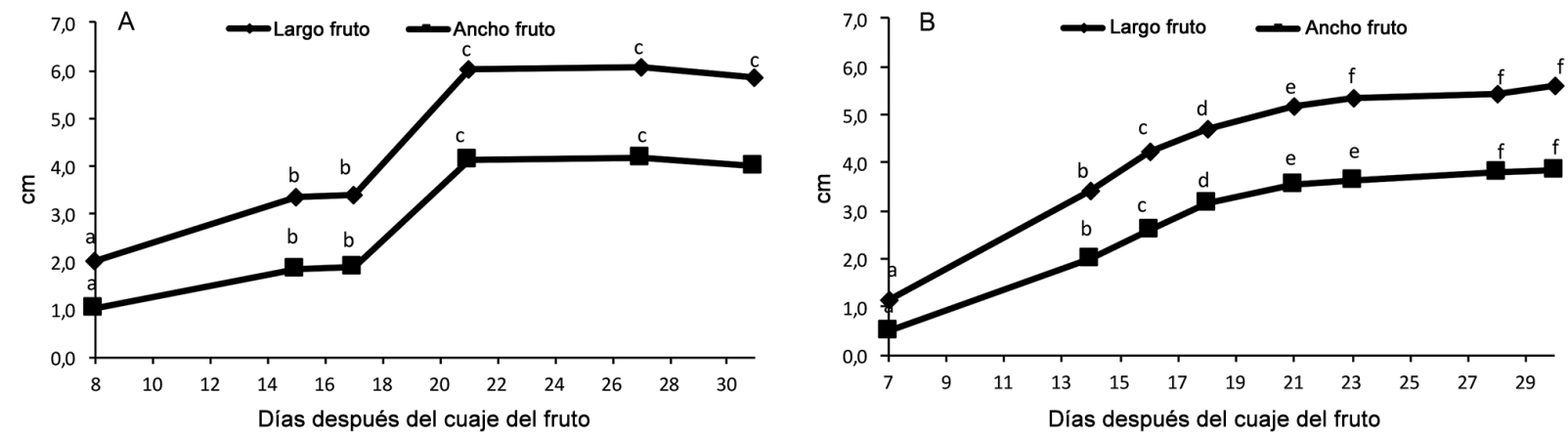

Figura 2. Largo y ancho de los frutos de tacaco (Sechium tacaco (Pittier) C. Jeffrey), con espinas (A) procedentes de El Yas de Paraíso, cosechados entre julio y agosto de 2014; sin espinas (B) procedentes de La Flor de Paraíso, cosechados entre enero y febrero de 2015. Cartago, Costa Rica.

Medias con letras iguales no difieren entre si, según análisis de varianza y la prueba DMS $(\mathrm{p}<0,05)$.

Figure 2. Length and width of tacaco fruits (Sechium tacaco (Pittier) C. Jeffrey), with thorns (A) from El Yas Paraíso, harvested between July and August 2014; and without thorns (B) from La Flor, Paraíso, harvested between January and February 2015. Cartago, Costa Rica.

Different letters mean statistical differences, according to variance analysis, LSD $(\mathrm{p}<0.05)$.

\section{Firmeza}

La firmeza del fruto incrementó a partir del día catorce en tacaco con espinas y desde el día diecisiete en frutos sin espinas, hasta alcanzar un máximo de 96,38 N y $129,87 \mathrm{~N}$, respectivamente (Figura 4). En tacaco sin espinas, este aumento se observó durante todo el período de evaluación, mientras que en frutos con espinas fue a partir de los diecisite y hasta los veintiún días donde se presentó este cambio en la firmeza.

\section{Fibra y presencia de espinas}

En ambos tipos de materiales evaluados, se observó la aparición de fibra a partir del día veintiuno (Figura 5), alcanzándose en tacacos con espinas un máximo 

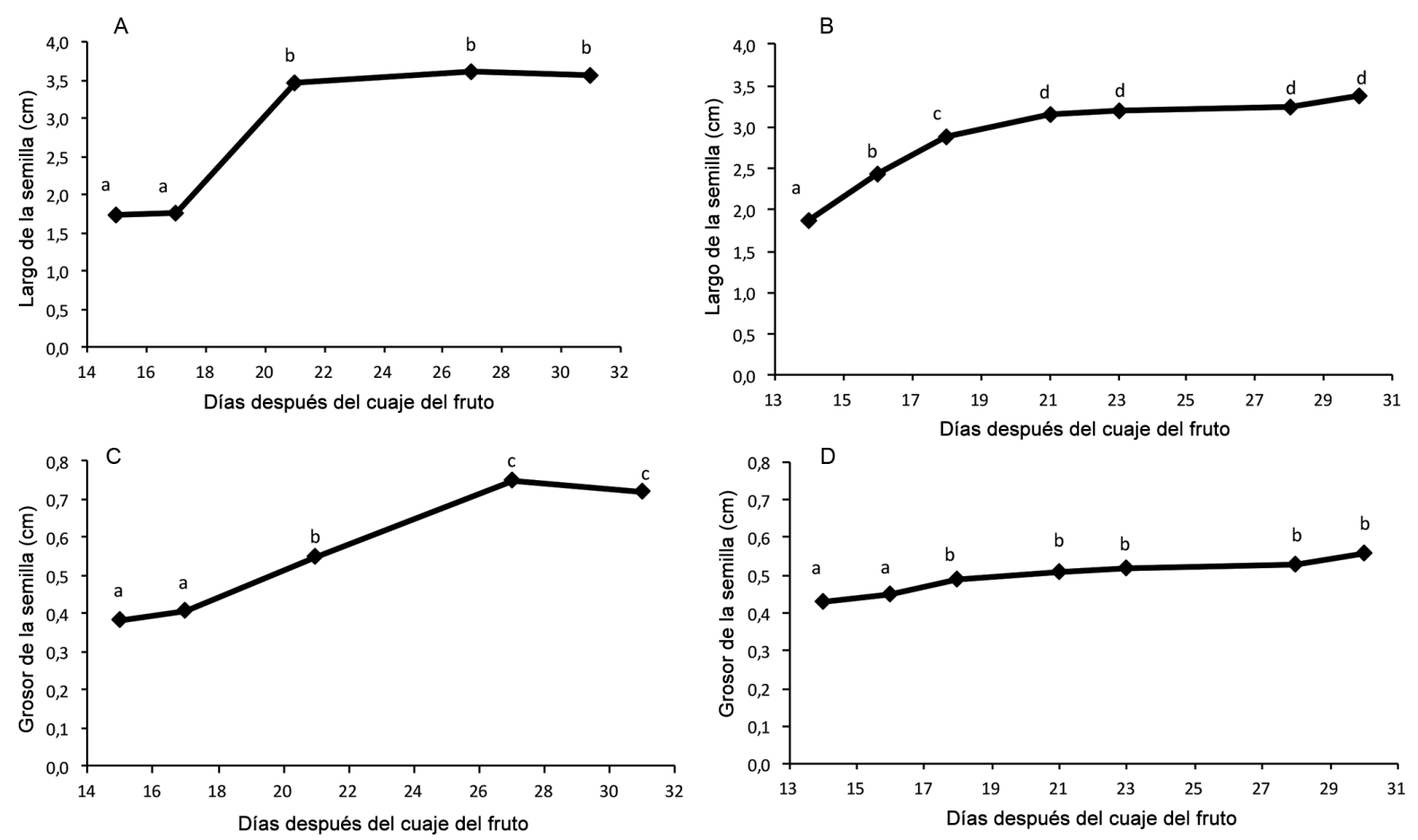

Figura 3. Largo y grosor de la semilla de tacaco (Sechium tacaco (Pittier) C. Jeffrey), con espinas (A y C) procedente de El Yas de Paraíso, cosechado entre julio y agosto de 2014; y sin espinas (B y D) procedente de La Flor de Paraíso, cosechados entre enero y febrero de 2015. Cartago, Costa Rica.

Medias con letras iguales no difieren entre si, según análisis de varianza y la prueba DMS $(\mathrm{p}<0,05)$.

Figure 3. Length and width of tacaco seeds (Sechium tacaco (Pittier) C. Jeffrey), with thorns (A and C) from El Yas Paraíso, harvested between July and August 2014, and without thorns (B and D) from La Flor, Paraíso, harvested between January and February 2015. Cartago, Costa Rica.

Different letters mean statistical differences, according to variance analysis, LSD $(\mathrm{p}<0.05)$.
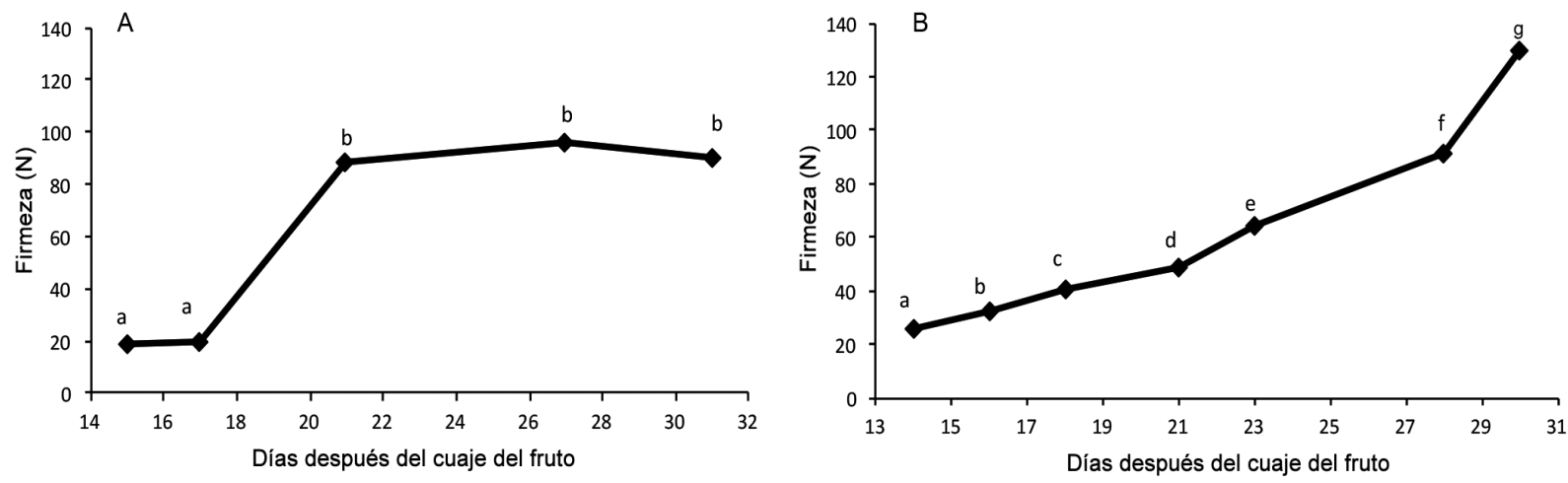

Figura 4. Firmeza (N) de los frutos de tacaco (Sechium tacaco (Pittier) C. Jeffrey), con espinas (A) procedentes de El Yas de Paraíso, cosechados entre julio y agosto de 2014, y sin espinas (B) procedentes de La Flor de Paraíso, cosechados entre enero y febrero de 2015. Cartago, Costa Rica.

Medias con letras iguales no difieren entre si, según análisis de varianza y la prueba DMS $(\mathrm{p}<0,05)$.

Figure 4. Firmness (N) of tacaco fruits (Sechium tacaco (Pittier) C. Jeffrey), with thorns (A) from El Yas Paraíso, harvested between July and August 2014, and without thorns (B) from La Flor, Paraíso, harvested between January and February 2015. Cartago, Costa Rica.

Different letters mean statistical differences, according to variance analysis, LSD $(\mathrm{p}<0.05)$. 

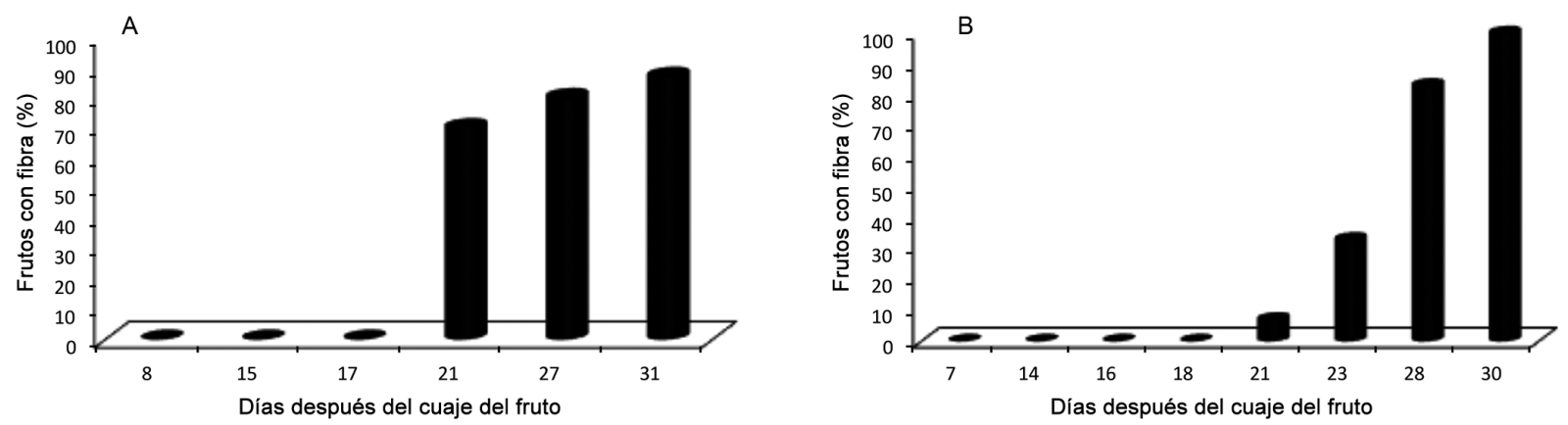

Figura 5. Presencia de fibra en tacacos (Sechium tacaco (Pittier) C. Jeffrey), con espinas (A) procedentes de El Yas de Paraíso, cosechados entre julio y agosto de 2014, y sin espinas (B) procedentes de La Flor de Paraíso, cosechados entre enero y febrero de 2015. Cartago, Costa Rica.

Figure 5. Presence of fiber in tacacos (Sechium tacaco (Pittier) C. Jeffrey), with thorns (A) from El Yas Paraíso, harvested between July and August 2014, and without thorns (B) from La Flor, Paraíso, harvested between January and February 2015. Cartago, Costa Rica.

de $87 \%$ de frutos con presencia de este tejido a los 31 días y un $100 \%$ a los treinta días en tacacos sin espinas. La aparición de espinas se dio a partir del día veintiuno (Figura 6) en el material procedente de El Yas de Paraíso, alcanzándose en ese momento un $23 \%$ de frutos con espinas suaves y un $67 \%$ de estos con espinas endurecidas, para el día 31 en un 100\% de los frutos se registró la presencia de estas estructuras. De acuerdo con un productor de la zona, las espinas dificultan los procesos de cosecha, empaque y limpieza del fruto, por lo que se prefiere materiales con pocas o sin presencia de estas estructuras (Valverde, comunicación personal, 2015). No obstante, es criterio de otro productor, que los materiales con espinas presentan una mayor productividad, por lo cual es necesario desarrollar investigaciones que permitan comparar estas y otras variables de productividad entre ambos tipos de materiales (Moya, comunicación personal, 2014).

El peso y las dimensiones del fruto son importantes para definir el índice de cosecha en frutas y vegetales, pero otros aspectos deben tomarse en cuenta para definir el uso final por parte del consumidor, entre estos, en tacaco es importante determinar el momento de formación de la fibra y la firmeza del mismo, aspectos que están relacionados con el uso del fruto, ya sea inmaduro o sazón. La pérdida de firmeza en frutas y hortalizas se encuentra directamente relacionada con la alteración enzimática de la lámina media y la pared celular, con un eventual incremento en la salida de

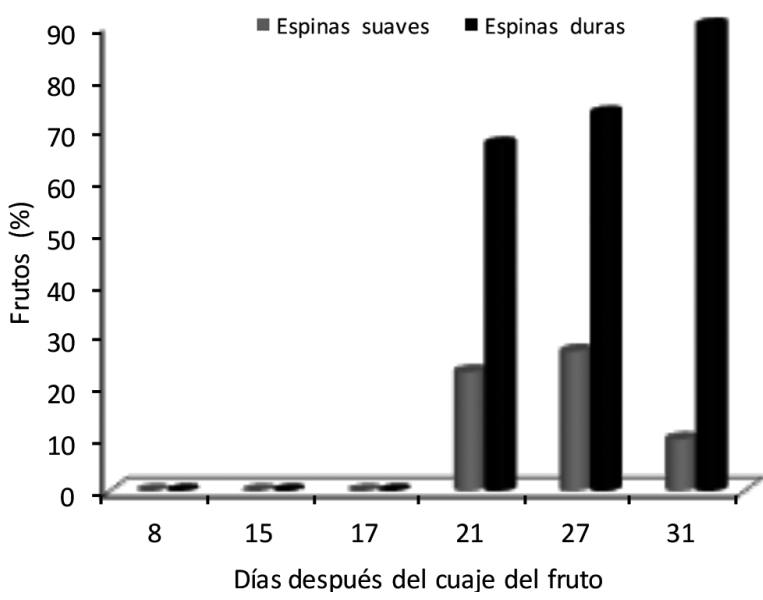

Figura 6. Presencia de espinas en frutos de tacaco (Sechium tacaco (Pittier) C. Jeffrey), procedentes de El Yas de Paraíso, cosechados entre julio y agosto de 2014. Cartago, Costa Rica.

Figure 6. Presence of thorns in tacaco fruits (Sechium tacaco (Pittier) C. Jeffrey), from El Yas, Paraíso, harvested between July and August 2014. Cartago, Costa Rica.

solutos de la célula (Proctor y Miesle, 1991; Brummell y Harpster, 2001), proceso en el que participan enzimas pécticas, como la pectin metilesterasa, y pectolíticas (endopoligalacturonasa y exopoligalacturonasa) (Kays, 1997; Mohd-Ali et al., 2004). En tacaco ocurre lo contrario, la firmeza se incrementa conforme el fruto 
crece y se da la aparición de fibra en el mesocarpo, tal y como se observó en ambos tipos de materiales, con una tendencia más definida en el tacaco sin espinas, donde tanto el porcentaje de frutos con fibra, como la firmeza, presentaron un incremento significativo entre los veintiuno y treinta días. Este comportamiento también ha sido observado en frutos de Spondias mangifera, en los cuales ocurre la lignificación de la pared celular secundaria (Sivaprasad et al., 2010).

La presencia de fibras en el mesocarpo es indeseable desde el punto de vista de consumo de este producto (Morales, 1994). De acuerdo con los resultados obtenidos, la detección de fibra a los veintiún días en ambos materiales y el incremento en la firmeza a los veintiún días en tacaco con espinas y a los veinticuatro en tacaco sin espinas, podría ser un indicador de cosecha para el fruto sazón, lo cual también coincidió con observaciones adicionales realizadas por los autores (datos no mostrados), donde se determinó que a los veintiuno y veinticuatro días, aproximadamente, un $83 \%$ de los frutos presentan un endurecimiento de la cáscara. Con respecto a la fibra, Morales (1994) señaló que el peso seco de la fibra varía desde cero en algunos frutos, hasta cerca de un gramo en los materiales que la poseen, aunque no indica el período de inicio de formación de la misma.

\section{Color externo}

El color externo desde los quince hasta los treinta días, que correspondió a fruto inmaduro y sazón respectivamente, mostró un cambio, desde un color verde amarillento hasta un verde grisáceo (imágenes del Cuadro 1). Se dio un incremento en el valor de $\mathrm{a}^{*}$, y una disminución en el croma $\left[\sqrt{ }\left(a^{2}+b^{2}\right)\right]$ y en el valor de $b^{*}$, lo cual se vio reflejado en el paso de un verde amarillento a un fruto con un color más oscuro y opaco, que se acentuó cerca de la abscisión del fruto y no en el momento de la aparición de la fibra y las espinas.

La caracterización poscosecha de frutos de tacaco permitió determinar que las dimensiones del fruto se incrementaron significativamente a partir del día catorce o diecisiete, dependiendo del material, y que otros cambios importantes relacionados con el uso culinario del mismo, como la aparición de fibra y espinas, y el incremento en la firmeza, ocurrieron a partir del día veintiuno o veintitres, cuando el fruto alcanzó sus dimensiones finales. Además, el color externo verde grisáceo fue un indicador de que el fruto se encontraba cercano al momento de abscisión, por lo que no coincidió con otros cambios importantes como la aparición de fibra y espinas.

Cuadro 1. Promedio de las mediciones de las variables de color externo $\mathrm{L}^{*}, \mathrm{a}^{*}, \mathrm{~b}^{*}$ y croma, escala CIELAB, en frutos de tacaco (Sechium tacaco (Pittier) C. Jeffrey), con espinas procedentes de El Yas de Paraíso, cosechados entre julio y agosto de 2014, y sin espinas procedentes de la Flor de Paraíso, cosechados entre enero y febrero de 2015. Cartago, Costa Rica.

Table 1. Average of external color variables measurements, $\mathrm{L}^{*}, \mathrm{a}^{*}, \mathrm{~b}^{*}$ and chroma, CIELAB scale, in tacaco fruits (Sechium tacaco (Pittier) C. Jeffrey), with thorns from El Yas, Paraíso, harvested between July and August 2014, and without thorns from La Flor, Paraíso, harvested between January and February 2015. Cartago, Costa Rica.

\begin{tabular}{lcccccc}
\hline Fruto & Días & $\mathbf{L}^{*}$ & $\mathbf{a}^{*}$ & $\mathbf{b}^{*}$ & Croma & \\
\hline \multirow{2}{*}{ Con espinas } & 15 & 48,75 & $-12,94$ & 29,52 & 32,23 & \\
& 31 & 39,79 & $-10,62$ & 19,96 & 22,61 & \\
\hline \multirow{2}{*}{ Sin espinas } & 14 & 41,67 & $-13,64$ & 19,7 & 23,96 & \\
& 30 & 43,21 & $-8,85$ & 16,39 & 18,63 & \\
\hline
\end{tabular}




\section{AGRADECIMIENTOS}

Los autores expresan su agradecimiento al Ing. Orlando Varela Ramírez, de la Escuela de Ciencias Agrarias de la Universidad Nacional de Costa Rica, por la colaboración ofrecida durante la realización de esta investigación.

\section{LITERATURA CITADA}

Brenes, A. 2002. Conservación de germoplasma de chayote (Sechium edule (Jacq) Swartz.) y tacaco (Sechium tacaco (Pittier) C. Jeffrey) como una base de apoyo para el mejoramiento genético y la producción de semillas. Universidad Nacional, Heredia, CRC.

Brenes, A., y S. Chaves. 1996. El tacaco en Costa Rica: erosión genética, erosión cultural. En: J. García, editor, Agronomía y recursos naturales. ¿Puede la agricultura ser competitiva?". EUNED/EUNA, San José, CRC. p. 300

Brenes, A., J.C. Saborío, O. Serrano, y W. Gamboa. 1996. Recolección, conservación y caracterización de germoplasma de Sechium en Costa Rica. En: J. García, editor, Agronomía y recursos naturales. ¿Puede la agricultura ser competitiva. EUNED/EUNA, San José, CRC. p. 299.

Brummell, D.A., and M.H. Harpster. 2001. Cell wall metabolism in fruit softening and quality and its manipulation in transgenic plants. Plant Mol. Biol. 47:311-340

Gamboa, W. 2005. Producción agroecológica, una opción para el desarrollo del cultivo de chayote (Sechium edule (Jacq.) Sw.). Editorial de la Universidad de Costa Rica, San José, CRC.

González, L. 2015. Cocina costarricense. http://www. recetasdecostarica.blogspot.com/ (consultado 7 ago. 2015).

INCAP (Instituto de Nutrición de Centroamérica y Panamá). 2007. Tabla de composición de alimentos de Centroamérica. 2 ed. INCAP/OPS, GUA.
INFOSTAT. 2012. Software estadístico. Universidad Nacional de Córdoba, ARG. http://www.infostat.com. ar/ (consultado 10 may. 2015).

Kays, S. 1997. Postharvest physiology of perishable plant products. Exon Press, USA.

León, J. 1987. Botánica de los cultivos tropicales. IICA, San José, CRC.

Lira, R. 1995. Estudios taxonómicos y ecogeográficos de las Cucurbitaceae latinoamericanas de importancia económica. International Board for Plant Genetic Resources (IBPGR), Universidad Autónoma de México (UNAM), MEX.

Minolta, K. 2007. Precise color communication: Color control from perception to instrumentation. Minolta Camera Co, JPN.

Missouri Botanical Garden. 2009. Manual de plantas de Costa Rica. The Cutting Edge XVI(3). http://www. mobot.org/MOBОT/research/Edge/ju109/jul09pick. shtml (consultado 7 ago. 2015).

Mohd-Ali, Z., L. Chin, and H. Lazan. 2004. A comparative study on wall degrading enzymes, pectin modifications and softening during ripening of selected tropical fruits. Plant Sci. 167:317-327.

Morales, J. 1994. Morfología general del tacaco, Sechium tacaco (Cucurbitaceae). Rev. Biol. Trop. 42(1/2):59-71.

Proctor, A., and T. Miesle. 1991. Polygalacturonase and pectinmethylesterase activities in developing highbush blueberries. HortSci. 26:579-581.

Ramírez, M.A., E. Valverde, y M.V. Sáenz. 1990. Estudio de algunos factores que afectan la fertilización de flores y la abscisión de frutos de chayote (Sechium edule Sw.) en cultivo en Costa Rica. Turrialba 40:340-345.

Sáenz, A. 1970. Historia agrícola de Costa Rica. Serie Agronomía $N^{\circ}$ 12. Universidad de Costa Rica, San José, CRC.

Sivaprasad, M., R.S. Policegoudra, and S.M. Aradhya. 2010. Biochemical changes associated with hardening of endocarp in Spondias mangifera Willd. fruits during developmental stages. Sci. Hort. 126:192-199. 